\title{
Vocal Cord Dysfunction after an Inhalation Exposure
}

\section{Stuart M. Brooks}

Emeritus Professor, University of South Florida, USA

*Corresponding author: Stuart M. Brooks, Colleges of Public Health and Medicine, University of South Florida, Tampa Florida, USA, E-mail: sbrooks@health.usf.edu Received date: June 26, 2017; Accepted date: July 20, 2017; Published date: July 29, 2017

Copyright: ( 2017 Brooks SM. This is an open-access article distributed under the terms of the Creative Commons Attribution License, which permits unrestricted use, distribution, and reproduction in any medium, provided the original author and source are credited.

\begin{abstract}
The manuscript embodies case material and the author's extensive personal experience to address a perceived or actual airborne exposure when incorrectly judged as due to intrathoracic/lung damage when in reality the outcome is the more innocuous extrathoracic/upper airway's vocal cord dysfunction (VCD). Because of the conviction of possible lung injury, the individual applies the fetal protective glottic closure reflex to counteract an odorant cue instigating acute VCD. Breathing against an obstructed glottis as well as hyperventilation from anxiety, panic and/or fear of personal harm worsens the laryngeal spasm. Spirometer shows flattening of the inspiratory loop of the flow-volume curve and endoscopy, while not done, would reveal adduction of the anterior two-thirds of the vocal cords with posterior chinking creating a diamond shape configuration. Successful therapy and management of VCD requires a speech therapy approach rather than physician prescribed medications.
\end{abstract}

Keywords: RADS; Vocal cord dysfunction; Odorants; Irritants; Inhalation injury; Asthma; Speech therapy

\section{Introduction}

This paper deals with vocal cord dysfunction (VCD), a clinical spectrum of entities mutual to the larynx in absence of local laryngeal organic disease. The clinical manifestations of VCD are because there is inappropriate adduction (closing) of the vocal cords (VC) during inspiration and sometimes also during expiration [1].

Over the past decade, the author has taken part in numerous cases of inhalation-related events with patients recounting acute respiratory complaints but subsequently established to manifest extrathoracic VCD. There are a variety of inhalation exposures to consider [2]. The inhalation exposure may incorrectly be ascribed as an intrathoracic condition such as reactive airways dysfunction syndrome (RADS) or new onset or exacerbation of preexisting asthma. Specific diagnostic criteria have been ascribed for RADS as well as for asthma [3,4]. Making a correct diagnosis of VCD is imperative because there are adverse therapeutic and economic consequences such as repeated emergency department visits, continued corticosteroid and bronchodilator administration, multiple hospitalizations and unwarranted physician interventions.

\section{Methods}

Over the past decade, the author has participated in dozens of inhalation-related cases asserted as being Reactive Airways Dysfunction Syndrome (RADS) or asthma. In some of the cases, the correct diagnosis is subsequently shown to be VCD. This paper builds on the author's experience on assessing inhalation exposures and proposes specific clinical clues for uncovering VCD ascribed to the inhalation exposure causing VCD. The paper suggests a unique pathogenetic mechanism for VCD development under the reported or assumed inhalational exposure circumstance. Finally, the text affords an appropriate literature review of VCD.

\section{Results}

There are four important clinical clues for better recognizing VCD following a claimed or actual inhalation exposure [1]. There are discrepancies, limited information and questionable facts about the exposure [2]. Smell hyper responsiveness is a frequent accompaniment of VCD after some inhalation exposures [3]. Voice loss or alteration is common for almost all cases of VCD [4]. There is the inexplicable failure to improve after sustained and appropriate treatment for an intrathoracic condition such as RADS or asthma.

The author's diagnostic suspicion rises when there is absent or lack of a clear identification of the inhalation exposure; or, when there is nonexistence of a massive exposure required for a RADS diagnosis. Regarding the latter, a massive, high-level exposure is an absolute diagnostic requirement for RADS [3]. There must be an unbiased analysis of the exposure determinants. The physician or health care provider does not just parrot the afflicted individual's account without objective analysis and documentation. Assessment requires identifying what exactly was in the exposure (i.e., constituents) and deliberates on how much of the constituent was generated (i.e., magnitude). Helpful information derives from analyzing other details of the exposure such as the chemical's physical properties (i.e., vapor pressure, $\mathrm{pH}$ and irritancy) and the exposure duration.

Dysphonia, hoarseness, voice change and/or some sort of impairment in the ability to produce voice sounds is because vocal folds fail to vibrate normally during exhalation. A satisfactory reduction in pressure, of at least $2-3 \mathrm{~cm} \mathrm{H}_{2} \mathrm{O}$, across the larynx permits lateral oscillation of the vocal folds. Voice is emitted as air is expelled through the glottis. But, there is almost no motion along the length of the vocal folds. In contrast, the vocal folds do not oscillate when fully closed (adducted) or when they are under too much tension such as with VCD. Under certain circumstances, the aryepiglottic folds take part in the singing or creating the vocal growl [5].

There is the inexplicable unresponsiveness to aggressive asthmatype treatment (i.e., inhaled corticosteroids, bronchodilators, oral/ parenteral corticosteroids) because the physician's decision to treat the 
Page 2 of 8

patient as having an intrathoracic condition is inappropriate. Rather, the diagnosis is incorrect since VCD is an extrathoracic malady and not a lung disorder.

The clinical course of VCD becomes more obvious under the clinical scenario of short-lived attacks lasting 30 seconds to a few minutes. Because of its transient nature and clinical similarities, VCD may simulate asthma [6]. Table 1 distinguishes differences between asthma and VCD. Asthmatic attacks are more sustained and last longer, usually minutes or hours before responding to treatment. Isolated attacks of bronchospasm cannot be considered as being asthma and rapidly developing inspiratory dyspnea tends to be selflimiting. Not all patients portray inspiratory wheezing and stridor. For some patients, there was a feeling mostly in the neck or upper trachea. Occasionally, there is difficulty in swallowing. Because vibrations of the two vocal cord edges create sounds, voice is lost or altered during vocal cord spasm.

What can be observed under the suspicious and unlikely clinical scenario when an intrathoracic injury is claimed to have occurred but in reality an extrathoracic event (e.g., VCD) is present? When first seen, the \% oxygen saturation of the patient with VCD is normal; and. the physical examination remains negative. There cannot be the inexplicable circumstances of an assumed, but not actual, high-level irritant gas, vapor or fume exposure asserted to have caused RADS. Unaccountably, the upper airways sites (i.e., eyes, nose and throat) are by-passed by the high-level irritant exposure, which is biologically impossible. Instead, there is absence, but expectation, of eye tearing and injection. Unlikely, the throat and nasal mucosal surfaces are not inflamed and/or reddened due an irritant exposure. No auscultation findings are heard listening to the chest with a stethoscope. Even though the physical examination of the chest, chest $\mathrm{x}$-ray interpretation and oxygen saturation are all negative/normal the diagnosis of RADS or asthma can persevere by the patient and health care provider. When an acute VCD attack is present, direct visualization of the vocal folds by flexible, trans nasal fiber-optic laryngoscopy represents the gold standard for the diagnosis of VCD $[1,7]$. Typically, there is closure of the anterior two-thirds of the vocal cords with posterior chinking that creates a diamond shape (Figure 1a and b). Sometimes, patients are instructed to perform various maneuvers including sniff, sequential phonation, normal breathing, panting and repetitive deep breaths in order to fully evaluate vocal cord movement [8]. In contrast, the author's cases relied on spirometry utilizing a visual flow-volume tracing. In our patients, the inspiratory loop of the flow-volume curve was truncated or showed flattening as demonstrated in Figure 2a and b [9]. We did not employ provocation testing to confirm abnormal vocal cords closure such as by using aerosolized methacholine, administering inhaled mannitol powder, performing strenuous exercise on a treadmill or bicycle ergometer, breathing in refrigerated cold air, or inhaling odorants/irritants, such as perfume or cleaning agents containing chlorine or ammonia [10,11]. Impulse oscillometry was not employed in any case [12].

Table 1 records the author's collective list of inhalation exposures ascribed to VCD. Molds are not considered an irritant and cannot cause RADS or any type of persistent irritant-induced inhalation injury. Chlorine dissolved in swimming pool water (as sodium hypochlorite) kills bacteria though a chemical reaction not by way of generating chlorine gas.
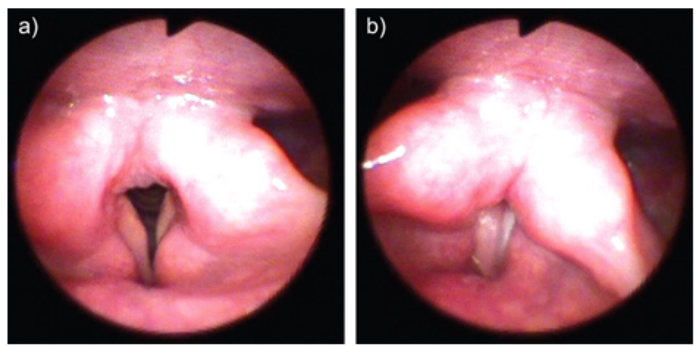

Figure 1: Classic vocal cord dysfunction with a) early paradoxical adduction of the vocal folds." (b) Complete closure of the vocal folds with formation of a posterior chink.
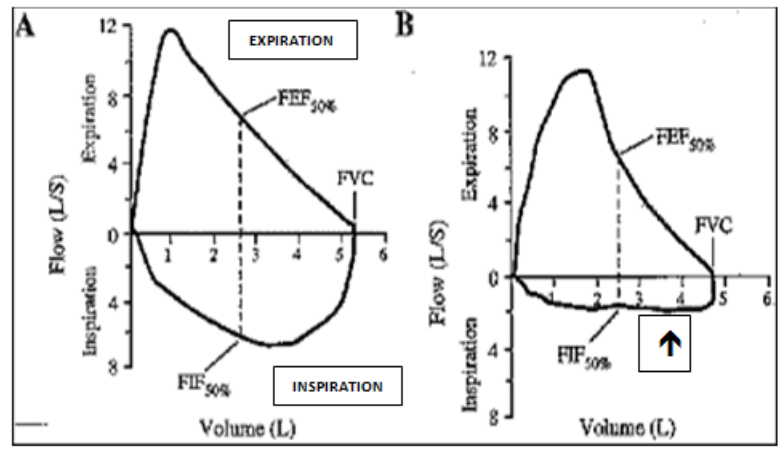

Figure 2: Example of a flow-volume loop in a normal subject (A) and in a patient with VCD (B). Note the blunting and flattening of the inspiratory loop of the flow-volume curve (arrow). Sometimes, there is a saw-tooth pattern. The ratio of the maximal inspiratory flow at $50 \%$ of the forced vital capacity (MIF50)/maximal expiratory flow at $50 \%$ of forced vital capacity (MEF50) that is less than one suggests a VCD related problem. Reduced FEV1 in proportion to FVC (FEV1/FVC \%) tends to be greater than $70 \%$. During VCD symptoms, an abrupt drop and rise in the expiratory flow volume loop may be observed in the absence of coughing.

\section{Causes of VCD after as inhalation exposure}

"Sick Building", "Mold(S) Exposure”; Occupancy in Water Damaged Building

Swimming Pool Environment; Chlorine Gas

Military Deployment

Exercising \& Competitive Sports

High Levels of Dust

Gastroesophageal Reflux (GERD)

Welding Fumes

Aerosolized Cleaning Solutions

Adhesive Vapors 
Page 3 of 8

\begin{tabular}{|l|}
\hline Glutaraldehyde \\
\hline Anhydrous Ammonia Or Ammonium-Containing Chemicals \\
\hline Steam and Dust in the Air \\
\hline Fire Resistant Powder Containing Ammonium-Containing Ingredients \\
\hline $\begin{array}{l}\text { Assumed Latex Antigen But Rather Vinyl Gloves are Present In An Examining } \\
\text { Room }\end{array}$ \\
\hline
\end{tabular}

Table 1: Causes of VCD after as inhalation exposure.

\section{Discussion}

Vocal Cord Basics: Important roles of the human larynx are to protect the lower airways from aspiration, facilitate respiration and participate in phonation. The larynx contains 3 unpaired relatively larger cartilages (epiglottis, thyroid and cricoid) that work with three smaller paired cartilages (arytenoids, corniculate and cuneiform). The make-ups of the larynx include the upper supraglottis structures, the mid-level glottis containing the vocal cords and the lower region of the subglottis. The upper supraglottis consists of the aryepiglottic fold, cuneiform tubercles and epiglottis that are supported by muscles, ligaments and membranes [13]. The triangular aryepiglottic folds are located at the entrance of the larynx. Ligamentous and muscular fibers permeate from the lateral borders of the epiglottis and attach to the arytenoid cartilages. During exercise, the epiglottis rotates forward towards the base of the tongue stretching the aryepiglottic folds [13]. During exercise, this action permits greater airflow with less airflow resistance with most of the air flow through the dorsal part of the glottic opening.

The smaller paired pyramidal-shaped laryngeal arytenoid cartilages, which attach to the folds of vocal cords, create a slit about $1 / 3$ inches wide [14]. There is external rotation of the arytenoid cartilages with widening (i.e., abduction) of the vocal cord slit during tidal inhalation. During this maneuver, the arytenoid cartilages slide, tilt and rotate along a vertical axis [13].

The posterior cricoarytenoid muscle is the major muscle for vocal cord opening. It activates 40 to 100 milliseconds before the inspiratory activation of the diaphragm. There are influencing signals from the brain's medullary center with connections running through the vagus nerve [15].

With VCD, there tends to be a fleeting obstruction of the upper airway maneuvered mainly by inspiratory closure of the vocal folds but also sometimes closing during expiration [1]. VCD manifests intensified closure of the glottic sphincter and perhaps inhibition of muscular abduction $[16,17]$. Accordingly, there is less tightening of the posterior cricoarytenoid muscle and greater lateral cricoarytenoid muscle action to further narrow the vocal cord slit by $10-40 \%$ [15,18-20]. The process may entail development of a perpetual hyperexcitable state as laryngeal-controlled neuronal networks react inappropriately to sensory messages from subcortical and other regions of the brain [21-26].

The VCD attack is distinctive since the glottic closure is greatly intensified by enhanced breathing patterns. Initially, there is a forced inspiration attempt against an obstructed and nearly closed glottis. The maneuver causes a strong negative intrathoracic pressure. Subsequent hyperventilation from anxiety and panic leads to faster and deeper breathing that lowers $\mathrm{pCO}_{2}$ (hypocapnia) and elevates airway and alveolar $\mathrm{pO}_{2}$ [27]. The trigger for the VCD is the awareness of a scent or odor. Shusterman and colleagues record two cases of recurrent panic attacks with hyperventilation following an exposure to odorant chemicals [28,29]. Ostensibly, the odorant chemical acts as a behavioral sensitizer triggering continuing anxiety and hyperventilation $[29,30]$. The up-shot of these breathing changes maximizes the intensity and duration of laryngospasm [17].

Causes of VCD: The true prevalence of VCD is somewhere in the neighborhood of 3 in 100 persons, falling between $2.5 \%$ and $2.8 \%$ [10]. Currently, the exact etiology of VCD following an inhalation exposure (or even VCD itself) remains unknown. There are no bio-chemical, physiologic or structural abnormalities identified [1]. The earliest portrayals of VCD were based mainly on case reports and small series. Earlier belief considered VCD as a psychological illness, a factitious entity, a hysterical neurosis or a somatoform disorder with "a loss of or alteration in physical functioning" [8,31-34]. Supposedly, unnamed stressors or an unidentified disturbance in both patient and family play significant roles in VCD pathogenesis. [5,35-37].

More attention to VCD came with the observation that the entity appeared more often among symptomatic population groups. The prevalence of $\mathrm{VCD}$ was $22 \%$ for persons requiring repeated emergency room visits due to sudden-onset shortness of breath [38]. The condition was observed in about $10 \%$ of patients seeking evaluation of asthma unresponsive to aggressive therapy $[39,40]$. VCD was mistaken for refractory asthma [33]. VCD prevalence among children and adolescents hospitalized because of asthma was as high as 14\%, [35,41].

Then, there were special population such as military inductees where roughly $15 \%$ of US-American military recruits with suspected asthma exhibited VCD $[42,43]$. In fact, military deployment became falsely equated as being an actual exposure rather than a time spent in a diverse foreign environment containing potentially dangerous exposures [44-46]. For the latter, investigations conducted by countries other than the United States submitted there were, in reality, preexisting asthma exacerbations from different environmental exposures (47:Katz I, 1999 \#12515, [47-56]).

Another special population comprised nearly $5 \%$ of US Olympic elite athletes who showed exercise-induced inspiratory stridor in cold, dry, ambient environments $[57,58]$. There arose special interest with the notice of VCD among female athletes [59]. VCD masquerading as an induced athletic entity became more evident when McFadden uncovered VCD among seven elite athletes presenting with acute dyspnea during sporting competitions [60]. As more research was introduced, exercise-induced bronchospasm seemed not to signify asthma or laryngospasm but rather could represent just poor support of muscles, ligaments and laryngeal cartilages [13]. At times it seemed that the diagnosis of exercise-induced bronchoconstriction was based solely on symptoms and medication use [61]. Supposedly, there were similarities between persons displaying exercise-induced VCD and persons experiencing exercise-induced laryngomalacia [62]. More extensive research suggested that exercise-induced inspiratory stridor could be an alternative movement of the supraglottic structures unresponsive to prescribed medications [57,63-65]. Under the latter situation, VCD might just be a physiologic alteration where breathing restriction begins in a supraglottic structures and VCD happens as a secondary phenomenon [13]. In fact, Turmel et al. utilized eucapneic voluntary hyperventilation to uncover cases of VCD and recommended dividing exercise-induced VCD into three categories: supraglottic, glottic and mixed (glottic and supraglottic) obstruction [63]. But besides VCD itself, there are other physiologic changes 
Page 4 of 8

associated with intense exercise. Nearly 40 to $50 \%$ of healthy elite cyclists and runners exhibit a significant reduction in arterial oxygenation during exercise at work rates approaching maximal oxygen consumption [66]. Mechanical stress may impair the functioning of the blood-gas barrier among elite athletes completing a short-term exercise event $[67,68]$.

Publications identified unique associations with VCD. Gastroesophageal reflex disorder (GERD) caused laryngospasm and sudden death in infants [69]. It seemed to play a role in the irritable larynx syndrome, a VCD-like condition [22,70]. There was resolution of VCD complaints after effective treatment of GERD [71]. A variety of irritant chemicals were said to induce VCD [72]. Eleven individuals manifesting voice change were initially considered to have RADS or asthma because there had been a temporal association between onset of respiratory symptom and prior occupational or environmental exposure [73]. The description of the exposures did not suggest a massive irritant gas, vapor or fume exposure essential in RADS development [74]. All 11 VCD patients had negative methacholine challenges but laryngoscopic evidence of VCD. Listed workplace exposures included ammonia, flux fumes after inappropriate mixing of flux and solder, aerosolized cleaning chemicals, an odor (cooked spicy salmon), organic solvent, aerosolized machining fluid and smoke and ceiling tile dust after a construction worker fell through the ceiling above the workstation. Respiratory disorders were claimed for swimming pool participants [75,76]. Some competitive swimmers develop VCD [59]. Children and adolescents who repeatedly swam, and were exposed to chlorine additives for water disinfection, could become symptomatic [75,77-82]. Apparently, chlorine dissolved in swimming pool water would not pose a danger for the majority of swimmers. Mostly, swimming pool disinfection requires added sodium hypochlorite and not chlorine gas. When sodium hypochlorite is added to the swimming pool water, it almost instantly produces hypochlorous acid. When sodium hypochlorite is added to the swimming pool water, it almost instantly produces hypochlorous acid. Possibly, higher levels of chlorine in the water might be instigated from the water surface of poorly vented indoor pools. Chlorine gas is rarely utilized for disinfecting swimming pools but chlorine gas by itself can lead to VCD [83-86]. Allan et al. reported on a firefighter exposed to a claimed railroad spill of 15,00 gallons of chlorine gas who developed progressive VCD [87].

There are the rare and sometimes baffling associations with VCD. Perkins described induction of VCD by methacholine challenge test [11]. Cummings and colleagues described 2 cases of VCD related to occupancy in water damaged buildings [88]. There is the report of a 46-year-old woman with VCD precipitated by eucalyptus exposure [89]. A 15 year old teen ager developed VCD while working in a corn field [90]. Less than a decade after the 09/11 terrorist attack, De la Hoz described VCD in about 10\% of former World Trade Center rescue and recovery workers and volunteers [91].

Anatomy of VCD Illness: Edward Shorter surveyed roughly 200 years of human illnesses by carefully interpreting (some material was not in English) and scrutinizing information contained in the medical records of physicians in Europe and the United States [92]. Shorter was of the opinion that the mind and attitude of some persons were capable of misinterpreting a stress or experience into a physical manifestation. Shorter suggested that medical conditions were often shaped by subtle past experiences, prevailing medical beliefs and contemporary cultural forces. A clearer understanding of VCD following an actual or assumed inhalation exposure necessitates assessing key exposure facts, identifying clinical subtleties of VCD, profiling the afflicted patient and appreciating physician or health care provider incentives and attitudes. Some of Shorter's contentions may hold weight for VCD.

First, let's focus on VCD among adults. The earliest lung defense mechanisms begins with the fetal glottic closure reflex, a protective strategy for preventing aspiration of amniotic fluid into the tracheobronchial tree and lungs during intrauterine life [16]. The human fetus regularly swallows amniotic fluid containing fetal lung fluid, fetal urine, debris from skin cells and particulate matter during intrauterine life $[93,94]$. By full-term gestation at 37 weeks, the fetus is capable of swallowing and circulating roughly $500 \mathrm{~mL}$ of amniotic fluid daily [69]. A relevant reason for the development of VCD after an inhalation exposure may epitomize the defensive desire to protect the lower lungs from a potentially "dangerous" inhalation. Perhaps, this seemingly abnormal alteration occurs in an overly susceptible individual among the general population. This possibility can present in adults because the fetal protective reflex of glottic closure is not eliminated after birth but continues during adulthood and is important for coughing when there is exhalation against a partially closed glottis in order to clear secretions and materials from the lower airways. A closed glottis participates in the Valsalva maneuver [95].

Second, what triggers VCD (i.e., glottic reflex) after an inhalation exposure? Our patients with VCD describe enhanced respiratory responsiveness to odorants and scents such as perfumes, cigarette smoke and incense. Ayres and Gabbott suggested that VCD involved laryngeal hyper responsiveness and heightened glottic closure due to intrinsic or extrinsic triggers [96]. Perhaps, the odor or scent elicited an acute VCD attack because it created a stressful experience and raised the worrisome belief that the airborne environmental chemical was dangerous even when its chemical concentration was far below the expected toxicity level [97]. The patient's perception and attribution of the smell influences or alters a more accurate interpretation of the exposure [97]. Odors can induce respiratory changes while at the same time promote emotion and memory [98]. Some persons are more likely to learn about subjective symptoms in response to odors while others do not [99]. An odor is a sensation caused by simulation of the olfactory organs. A volatile odorant molecule approximates the 2 inchsquare sensitive olfactory membranes present in each nostril that initiates nerve impulses to the olfactory bulb located at the base of the frontal lobe of the brain $[100,101]$. Odorant-alerting properties of nasal receptors can heighten the sensitivity of laryngeal reflexes $[25,102,103]$. Odors induce respiratory changes while at the same time promote emotion and memory [98]. Odorant-alerting properties of nasal receptors heighten the sensitivity of laryngeal reflexes [25,102,103]. Evidently, the alteration arises because more neural signals pass between the olfactory receptors and the olfactory cortex [104].

Next, let's discuss what makes the person with VCD different, perhaps he/she is one of the vulnerable or "susceptible" individuals in the general population [92]. But, "susceptible" does not necessarily pertain to a hysterical or abnormal psychological persona. Putatively, VCD occurrence after a perceived or actual inhalation event simply captures a subset of individuals in the general population who possess personality "susceptibility" rather than a preexisting psychiatric illness. How and why the "susceptible" person reverts to a glottic retort, formerly active during fetal development for protecting the lung against aspiration, is not clear. The odorant causes acute vocal cord spasm because the patient's aim is to "protect" the lungs from inhaling a perceived "toxic" constituent. 
Page 5 of 8

It takes two to tango so let's address the physician or health care provider. There is no medical reward when the condition is not accepted as being serious. The afflicted individual seeks care from a physician or health care professional in an Urgent Care Facility or Emergency Department for treatment/management of symptoms due to vocal cord spasm. The convinced patient communicates their symptoms to the receptive physician who pieces the puzzling events together but reaches an inappropriate conclusion. The pieces of the puzzle become more recognizable when fitted differently. Because the clinical picture simulates RADS or asthma, the consulted pulmonary specialist or emergency care provider institute asthma medications. Table 2 offers information differentiating asthma from VCD. The clinical label may continue for several years until the medical condition is more correctly diagnosed as VCD. Shorter's contention is especially fitting for the treating or consulting physician whose interpretation skills are fashioned by training, knowledge, experience and cultural influences [92]. The physician may inappropriately apply a difficult-todiagnose disorder such as VCD because of inaccurate understanding or misinterpretation of scientific/medical information. Regrettably, some practicing physicians are inadequately trained in the intricacies of inhalation injuries and chemical exposures. There may be insufficient or actual disregard for the basic toxicological principle of dose-response. Analysis of the inhalation exposure, particulars of chemical reactions, toxicological doctrines and what constitutes a massive exposure represent knowledge-gaps for some practicing physicians.

\begin{tabular}{|c|c|c|}
\hline \multirow[t]{2}{*}{ Onset } & Asthma & VCD \\
\hline & Minutes & Seconds \\
\hline Duration & Variable, minutes, hours or days & Short, seconds to a few minutes \\
\hline Dyspnea Development & Usually expiration & Usually inspiration \\
\hline Response to odorant & Occasionally & Frequent \\
\hline Auscultation & Expiratory \& inspiratory wheezing & Inspiratory wheezing/stridor \\
\hline Affected Site & Lower respiratory tract & Neck and/or throat \\
\hline Spirometry & Flattening of inspiratory loop of flow-volume loop & Reduced FEV1/FVC\% \& expiratory airflow obstruction \\
\hline Endoscopy & Bronchial mucosal erythema, edema and secretion & Vocal cord anterior $2 / 3$ adduction with posterior chinking \\
\hline Inhaled drug therapy & Effective & Ineffective \\
\hline Triggers & Irritants, allergens, exertion & Odorants, exercise, cold air, irritants, stress \\
\hline Cough & Persistent & Recurrent \\
\hline
\end{tabular}

Table 2: Typical clinical manifestations differentiating asthma and VCD.

\section{Management}

The cornerstone and most appropriate treatment for VCD is speech therapy $[8,105]$. Speech therapy utilizes techniques such as relaxedthroat breathing, respiratory retraining therapy and counseling on vocal hygiene [106]. Patients are coached to practice relaxation technique several times a day without manifesting stridor or chest tightness [8]. Sometimes, employing biofeedback clarifies the correlation between the patient's throat-related tension and autonomic hyperarousal. Biofeedback with relaxation training is especially of value for patients whose intensity of anxiety contributes to VCD symptomatology. Symptoms of VCD significantly recuperate with interventional speech therapy [107].

Phonatory tests, videostroboscopy and laryngeal image analysis are tests available for the VCD investigation [108,109]. Videostroboscopy is particularly beneficial since a steel scope containing a tiny camera and strobe light is placed in the patient's mouth. Figure 3 shows a patient undergoing videostroboscopy. The camera is angled to allow a clear and painless view of the patient's throat enabling a videotape of vocal cord movement and vibration in slow motion. The camera projects a moving image of the vocal cords, frame by frame, onto the television monitor. These images can be retrieved instantly as a video recording or as a still photo.
There is a technique for better controlling an acute VCD attack [8]. First, as soon as the patient feels an acute VCD attack is eminent then slowly breathe in through their nose. Certainly do not breathe in through the mouth. Second, exhale quickly out the mouth with pursed lips. Finally, continue slow nasal inhalation and quick mouth exhalation with pursed lips until the episode passes. Why does the method for the acute VCD attack work? For some reason, nasal breathing reinforces the brain to keep the vocal cords apart when inhaling. Quick inhalation through the mouth seems to do the opposite. Terminate oral hyperventilation, which may aggravate vocal cords closure. Slow breathing helps keep the vocal cords apart.

If speech therapy is not successful in controlling VCD symptoms during an acute attack, then helium-oxygen mixture (70\% helium, 30\% oxygen) can be incorporated during breathing. Helium, a light gas that more easily passes through areas of high airflow turbulence, relieves dyspnea and/or partially or completely ablates the acute VCD attack [8]. Possibly, psychological and psychiatric management can include behavioral, psychodynamic and/or pharmacological treatment modalities [110]. Marital or family counseling may be beneficial. For patients with a significant mood or anxiety disorder, antidepressant or anxiolytic treatment can be added to treatment. In the very rare case of severe VCD where the patient develops significant hypoxia during an acute VCD attack and is unresponsive to appropriate speech, psychological and medical therapy, tracheostomy can be an alternative 
Page 6 of 8

modality [8]. Other more radical treatments include sectioning of the laryngeal nerve and paralysis of the ipsilateral vocal cord [8] Anticholinergics may be a helpful adjunct in patients with exerciseinduced vocal cord dysfunction. In a series of six patients receiving pretreatment with inhaled ipratropium (Atrovent), all patients reported improvement of symptoms [111].

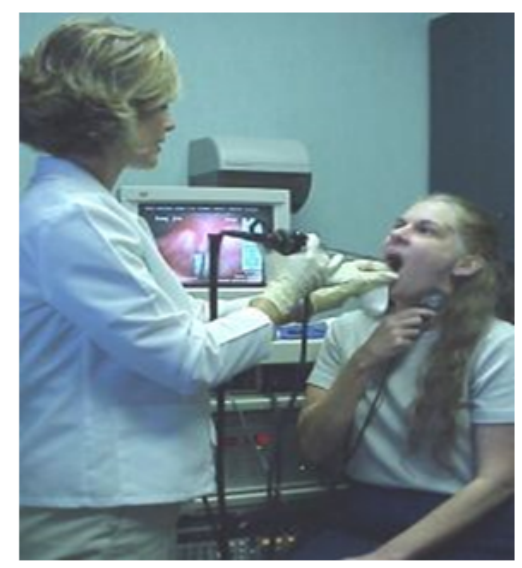

Figure 3: A patient undergoing videostroboscopy where a steel scope containing a tiny camera and strobe light is placed in the patient's mouth. The camera is angled to allow a clear and painless view of the patient's throat enabling a videotape of vocal cord movement and vibration in slow motion. The camera projects a moving image of the vocal cords, frame by frame, onto the television monitor. These images can be retrieved instantly as a video recording or as a still photo.

\section{Conflicts of Interest}

I certify that I (Stuart M. Brooks, MD) am the guarantor and only corresponding author who holds no potential conflicts of interest; no sources of funding and support; no information on statistical analyses; correct name/participation/degree/institution of the only author. I also certify that I did not accept compensation for inclusion of any of the statements contained in the manuscript.

\section{References}

1. Dunn NM, Katial RK, Hoyte FCL (2015) Vocal cord dysfunction: a review. Asthma Res Pract 1: 9.

2. Brooks SM (2013) Prospective and management: acute nonimmunologic inhalation injuries. J Occup Environ Med 55: 853-855.

3. Brooks SM, Weiss MA, Bernstein IL (1985) Reactive airways dysfunction syndrome. Case reports of persistent airways hyperreactivity following high-level irritant exposures. J Occup Med 27: 473-476.

4. Anderson SD, Brusasco V, Haahtela T, Popov T (2005) Chapter 6. Criteria for diagnosis of asthma, EIB and AHR for athletes: Lessons from the Olympic games Respiratory Society Monograph 33: 46-66.

5. Sakakibara KI, Fuks L, Imagawa HNT (2004) Growl voice in ethnic and pop styles. In: NTT Communication Science Laboratories NC Proceedings of the International Symposium on Musical Acoustics. Japan.

6. Bahrainwala AH, Simon MR (2001) Wheezing and vocal cord dysfunction mimicking asthma. Curr Opin Pulm Med 7: 8-13.
7. Kenn K, Hess MM (2008) Vocal cord dysfunction. An important differential diagnosis of bronchial asthma. Dtsch Arztebl Int 105: 699-700.

8. Newman KB, Dubester SN (1994) Vocal cord dysfunction: Masquerader of asthma. Seminars in Respir Crit Care Med 15.

9. Vlahakis NE, Patel AM, Maragos NE, Beck KC (2002) Diagnosis of vocal cord dysfunction: the utility of spirometry and plethysmography. Chest 122: 2246-2249.

10. Kenn K, Balkissoon R (2011) Vocal cord dysfunction: what do we know?. Eur Respir J 37: 194-200.

11. Perkins PJ, Morris MJ (2002) Vocal cord dysfunction induced by methacholine challenge test. Chest 122: 1988-1993.

12. Komarow HD, Young M, Nelson C, Metcalfe DD (2013) Vocal cord dysfunction as demonstrated by impulse oscillometry. J Allegy Clin Immunol Pract 1:387-393.

13. Røksund OD, Heimdal JH, Olofsson J, Maat RC, Halvorsen T, et al. (2015) Larynx during exercise: the unexplored bottleneck of the airways. Eur Arch Otorhinolaryngol 272: 2101-2109.

14. Gray H. Anatomy of the human body-1a. The larynx.

15. Ibrahim WH, Gheriani HA, Almohamed AA, Raza T (2007) Paradoxical vocal cord motion disorder: past, present and future. Postgrad Med J 83: 164-172.

16. Ikari T M, Sasaki CT (1980) Glottic closure reflex: Control mechanisms. Ann Otol Rhinol Laryngol 89: 220-224.

17. Sasaki IT (1980) Glottic closure reflex: control mechanisms. Ann Otol Rhinol Laryngol 89: 220-224.

18. Gacek RR, Malmgren LT, Lyon MJ (1977) Localization of adductor and abductor motor nerve fibers to the larynx. Ann Otol Rhinol Laryngol 86: 771-776.

19. Negus VE (1937) The Evidence of Comparative Anatomy on the Structure of the Human Larynx: (Section of Laryngology). Proc R Soc Med 30: 1394-1396.

20. Sasaki CT (2006) Anatomy and development and physiology of the larynx. In: Goyal R, R. S, editors. Shaker and Goyal GI Motility onlinePart 1 Oral cavity, pharynx and esophagus. London: Nature Publishing Group.

21. Simonyan K, Tovar-Moll F, Ostuni J, Hallett M, Kalasinsky VF, et al. (2008) Focal white matter changes in spasmodic dysphonia: A combined diffusion tensor imaging and neuropathological study. Brain 131: 447-459.

22. Morrison M, Rammage L, Emami AJ (1999) The irritable larynx syndrome. J Voice 13: 447-455.

23. Opiekun RE, Smeets M, Sulewski M, Rogers R, Prasad N, et al. (2003) Assessment of ocular and nasal irritation in asthmatics resulting from fragrance exposure. Clin Exp Allergy 33: 1256-1265.

24. Sasaki CT, Suzuki M (1977) Laryngeal spasm: A neurophysiologic redefinition. Ann Otol Rhinol Laryngol 86: 150-157.

25. Rombaux P, Mouraux A, Bertrand B, Guerit JM, Hummel T, et al. (2006) Assessment of olfactory and trigeminal function using chemosensory event-related potentials. Neurophysiol Clin 36: 53-62.

26. Kayser J, Tenke CE, Malaspina D, Kroppmann CJ, Schaller JD, et al (2010) Neuronal generator patterns of olfactory event-related brain potentials in schizophrenia. Psychophysiology 47: 1075-1086.

27. Dager SR, Holland JP, Cowley DS, Dunner DL (1987) Panic disorder precipitated by exposure to organic solvents in the work place. Am J Psychiatry 144: 1056-1058.

28. Shusterman D (2001) Odor-associated health complaints: Competing explanatory models. Chem Senses 26: 339-343.

29. Shusterman D, Balmes J, Cone J (1988) Behavioral sensitization to irritants/odorants after acute overexposures. J Occup Med 30: 565-567.

30. Shusterman D, Dager SR (1991) Prevention of psychological disability after occupational respiratory exposures. Occup Med 6: 11-27.

31. Brugman SM, Simons SM (1998) Vocal cord dysfunction: Don't mistake it for asthma. Phys Sportsmed 26: 63-85. 
Page 7 of 8

32. Patterson R, Schatz M, Horton M (1974) Munchausen's stridor: Nonorganic laryngeal obstruction. Clin Allergy 4: 307-310.

33. Leo RJ, Konakanchi R (1999) Psychogenic respiratory distress: A case of paradoxical vocal cord dysfunction and literature review. Prim Care Companion J Clin Psychiatry 1: 39-46.

34. Anbar RD, Hehir DA (2000) Hypnosis as a diagnostic modality for vocal cord dysfunction. Pediatrics 106: 1-3.

35. Gavin LA, Wamboldt M, Brugman S, Roesler TA, Wamboldt F, et al. (1998) Psychological and family characteristics of adolescents with vocal cord dysfunction. J Asthma 35: 409-417.

36. Harding SM (2005) Gastroesophageal reflux: A potential asthma trigger. Immunol Allergy Clin North Am 25: 131-148.

37. Poonai N, Antony MM, Binkley KE, Stenn P, Swinson RP, et al. (2000) Carbon dioxide inhalation challenges in idiopathic environmental intolerance. J Allergy Clin Immunol 105: 358-363.

38. Jain S, Bandi V, Zimmerman J, Hanania N, Guntupalli K, et al. (1999) Incidence of vocal cord dysfunction in patients presenting to emergency room with acute asthma exacerbation. Chest 11: 243.

39. Le AV, Simon RA (2006) The difficult-to-control asthmatic: A systematic approach. Allergy Asthma Clin Immunol 2: 109-116.

40. Morgan MDL (2002) Dysfunctional breathing in asthma: Is it common, identifiable and correctable?. Thorax 57: 31-35.

41. Brugman S (2003) The many faces of vocal cord dysfunction. What 36 years of literature tells us. Am J Respir Crit Care Med 167: A588.

42. Morris MJ, Oleszewski RT, Sterner JB, Allan PF (2013) Vocal cord dysfunction related to combat deployment. Mil Med 178: 1208-1213.

43. Morris MJ, Zacher LL, Jackson DA (2011) Investigating the respiratory health of deployed military personnel. Mil Med 176: 1157-1161.

44. Abraham JH, DeBakey SF, Reid L, Zhou J, Baird CP, et al. (2012) Does deployment to iraq and afghanistan affect respiratory health of us military personnel?. J Occup Environ Med 54: 740-745.

45. Szema AM, Peters MC, Weissinger KM, Gagliano CA, Chen JJ (2010) New-onset asthma among soldiers serving in Iraq and Afghanistan. See comment in PubMed Commons below Allergy Asthma Proc 31: 67-71.

46. Falvo MJ, Bradley M, Brooks SM (2014) Is deployment an "exposure" in military personnel? See comment in PubMed Commons below J Occup Environ Med 56: e139-140.

47. Nish WA, Schwietz LA (1992) Underdiagnosis of asthma in young adults presenting for usaf basic training. Ann Allergy 69: 239-242.

48. Anderson SD (2011) Exercise-induced bronchoconstriction in the 21st century. J Am Osteopath Assoc 111: S3-S10.

49. Carlsen KH, Anderson SD, Bjermer S, Bonini S, Brusasco V, et al. (2008) Exercise-induced asthma, respiratory and allergic disorders in elite athletes: Epidemiology, mechanisms and diagnosis: Part I of the report from the joint task force of the European Respiratory Society (ERS) and the European Academy of Allergy And Clinical Immunology (EAACI) in cooperation with ga2len. Allergy 3: 387-403.

50. Roorda RJ, Gerritsen J, van Aalderen WMC, Schouten JP, et al. (1994) Follow-up of asthma from childhood to adulthood: Influence of potential childhood risk factors on the outcome of pulmonary function and bronchial responsiveness in adulthood. J Allergy Clin Immunol 93: 575-584.

51. Sears MR (2012) Predicting new and persistent asthma. Am J Respir Crit Care Med 186: 469-470.

52. Sinclair DG, Sims MM, Hoad NA, Winfield CR (1995) Exercise-induced airway narrowing in army recruits with a history of childhood asthma. Eur Respir J 8: 1314-1317.

53. Kivity S, Shochat Z, Bressler R, Wiener M, Lerman Y, et al. (1995) The characteristics of bronchial asthma among a young adult population. Chest 108: 24-27.

54. Adams R, Wilson D, Appleton S, Taylor A, Dal G, et al. (2003) Underdiagnosed asthma in south australia. Thorax 58: 846-850.

55. Dickinson JG (1988) Asthma in the army: A retrospective study and review of the natural history of asthma and its implications for recruitment. JR Army Med Corps 134: 65-74.
56. Brooks SM (2015) Occupational medicine model and asthma military recruitment. Mil Med 180: 1140-1146.

57. Rundell KW, Slee JB (2008) Exercise and other indirect challenges to demonstrate asthma or exercise-induced bronchoconstriction in athletes. J Allergy Clin Immunol 122: 238-246.

58. Rundell KW, Spiering BA (2003) Inspiratory stridor in elite athletes. Chest 123: 468-474.

59. Wilson J, Theis SM, Wilson EM (2009) Evaluation and management of vocal cord dysfunction in the athlete. Curr Sports Med Rep 8: 65-70.

60. McFadden ER Jr, Zawadski DK (1996) Vocal cord dysfunction masquerading as exercise-induced asthma. A physiologic cause for "choking" during athletic activities. Am J Respir Crit Care Med 153: 942-947.

61. Holzer K, Anderson SD, Douglass J (2002) Exercise in elite summer athletes: Challenges for diagnosis. J Allergy Clin Immunol 110: 374-380.

62. Tilles SA, Ayars AG, Picciano JF, Altman K (2013) Exercise-induced vocal cord dysfunction and exercise-induced laryngomalacia in children and adolescents: The same clinical syndrome?. Ann Allergy Asthma Immunol 111: 342-346.

63. Turmel J, Gagnon S, Bernier M, Boulet LP (2015) Eucapnic voluntary hyperpnoea and exercise-induced vocal cord dysfunction. BMJ Open Sport Exerc Med 1: e000065.

64. Bussotti M, Di Marco S, Marchese G (2014) Respiratory disorders in endurance athletes - how much do they really have to endure?. Open Access J Sports Med 5: 47-62.

65. Newsham KR, Klaben BK, Miller VJ, Saunders JE (2002) Paradoxical Vocal-Cord Dysfunction: Management in Athletes. J Athl Train 37: 325-328.

66. Powers SK, Martin D, Dodd S (1993) Exercise-induced hypoxaemia in elite endurance athletes. Sports Med 16: 14-22.

67. Hopkins SR, Schoene RB, Henderson WR, Spragg RG, Martin TR, et al. (1997) Intense exercise impairs the integrity of the pulmonary blood-gas barrier in elite athletes. Am J Crtit Care Med 155: 1090-1094.

68. Wanivenhaus F, Fox AJ, Chaudhury S, Rodeo SA (2012) Epidemiology of injuries and prevention strategies in competitive swimmers. Sports Health 4: 246-251.

69. Jadcherla SR, Hogan WJ, Shaker R (2010) Physiology and pathophysiology of glottic reflexes and pulmonary aspiration: From neonates to adults. Semin Respir Crit Care Med 31: 554-560.

70. Fonkalsrud EW, Ament ME (1996) Gastroesophageal reflux in childhood. Curr Probl Surg 33: 1-70.

71. Bucca C, Rolla G, Scappaticci E, Chiampo F, Bugiani M, et al. (1995) Extrathoracic and intrathoracic airway responsiveness in sinusitis. J Allergy Clin Immunol 95: 52-59.

72. Marcinow A, Thompson J, Forrest L, DeSilva BW (2015) Irritant-induced paradoxical vocal fold motion disorder: Diagnosis and mangement. Otolaryngol Head Neck Surg 153: 996-1000.

73. Perkner JJ, Fennelly KP, Balkissoon R, Bartelson BB, Ruttenber AJ, et al. (1998) Irritant-associated vocal cord dysfunction. J Occup Environ Med 40: 136-143.

74. Bardana EJ (1999) Reactive airways dysfunction syndrome (RADS): Guidelines for diagnosis and treatment and insight into likely prognosis. Ann Allergy Asthma Immunol 83: 583-586.

75. Bernard A, Nickmilder M, Voisin C, Sardella A (2009) Impact of chlorinated swimming pool attendance on the respiratory health of adolescents. Pediatrics 124: 1110-1118.

76. Nemery B, Nowak HD (2002) Indoor swimming pools, water chlorination and respiratory health. Eur Respir J 19: 790-793.

77. Weisel CP, Richardson SD, Nemery B, Aggazzotti G, Baraldi E, et al. (2009) Childhood asthma and environmental exposures at swimming pools: State of the science and research recommendations. Environ Health Perspect 117: 500-507.

78. Thickett KM, McCoach JS, Gerber JM, Sadhra S, Burge PS, et al. (2002) Occupational asthma caused by chloramines in indoor swimming-pool air. Eur Respir J 19: 827-832. 
Page 8 of 8

79. Massin N, Bohadana AB, Wild P, Hery M, Toamain JP, et al. (1998) Respiratory symptoms and bronchial responsiveness in lifeguards exposed to nitrogen trichloride in indoor swimming pools. Occup Environ Med 55: 258-263.

80. Bougault V, Turmel J, Bertrand SLM, Boulet LP (2009) Asthma, airway inflammation and epithelial damage in swimmers and cold-air athletes. Eur Respir J 33: 740-746.

81. Babu RV, Cardenas Jr V, Sharma G (2008) Acute respiratory distress syndrome from chlorine inhalation during a swimming pool accident: A case report and review of the literature. J Intensive Care Med 23: 275-280.

82. Bar-Or O, Inbar O (1992) Swimming and asthma. Benefits and deleterious effects. Sports Med 14: 397-405.

83. Bhargava S, Panitch HB, Allen JL (2000) Chlorine induced paradoxical vocal cord dysfunction. Chest 118: 295S-296S.

84. McNicol KN, Williams HB (1975) The spectrum of asthma in children Pediatr Clin North Am 22: 43-52.

85. Reddy PV, Solomon D, Truncale T (2004) Vocal cord dysfunction after chlorine inhalation. Chest: p. 999S.

86. Prakash V, Reddy MD, Solomon D, Truncale T (2004) Vocal cord dysfunction after chlorine inhalation. In: Physician ACCP, editor. Annual Meeting of the American College of Chest Physician. Dallas Texas: American College of Chest Physician: p. 999S.

87. Allan PF, Abouchahine S, Harvis L, Morris MJ (2006) Progressive vocal cord dysfunction subsequent to a chlorine gas exposure. J Voice 20: 291-296.

88. Cummings K, Fink J, Vasudev M, Piacitelli C, Kreiss K (2013) Vocal cord dysfunction related to water-damaged buildings. J Allergy Clin Immunol Pract 1: 46-50.

89. Huggins JT, Kaplan A, Martin-Harris B, Sahn SA (2004) Eucalyptus as a specific irritant causing vocal cord dysfunction. Ann Allergy Asthma Immunol 93: 299-303.

90. Weinberger M, Doshi D (2017) Vocal cord dysfunction: a functional cause of respiratory distress. Breathe (Sheff) 13: 15-21.

91. De la Hoz RE, Shohet MR, Bienenfeld LA, Afilaka AA, Levin SM, et al. (2008) Vocal cord dysfunction in former world trade center (wtc) rescue and recovery workers and volunteers. Am J Ind Med 51: 161-165.

92. Shorter E (1992) From paralysis to fatigue: A history of psychosomatic illness in the modern era. The Free Press, New York.

93. Allen J (2003) Statement on the Care of the Child with Chronic Lung Disease of Infancy and Childhood. Am J Respir Crit Care Med 168: 356-396.

94. Jadcherla RJ, Gupta A, Coley BD, Fernandez S, Shaker R (2007) Esophago-glottal closure reflex in human infants: A novel reflex elicited with concurrent manometry and ultrasonography. Am J Gastroenterol 102: 2286-2293.

95. Sasaki H, Sekizawa K, Yanai M, Arai H, Yamaya M, et al. (1997) New strategies for aspiration pneumonia. Intern Med 36: 851-855.
96. Ayres JG, Gabbott PLA (2002) Vocal cord dysfunction and laryngeal hyperresponsiveness: a function of altered autonomic balance?. Thorax 57: 284-285.

97. Smeets MA, Dalton P (2005) Evaluating the human response to chemical: Odor, irritation and non-sensory factors. Environ Toxicol Pharmac 19: 581-588.

98. Masaoka Y, Homma I (2010) Respiratory response toward olfactory stimuli might be an index for odor-induced emotion and recognition. Adv Exp Med Biol 669: 347-52.

99. Bergh OVD, Stegen K, Diest IV, Raes C, Stulens P, et al. (1999) Acquisition and extinction of somatic symptoms in response to odours: A pavlovian paradigm relevant to multiple chemical sensitivity. Occup Environ Med 56: 295-301.

100. Emsenhuber B (2011) The olfactory medium Science, Technology \& Innovation Studies 7: 47-64.

101. Shusterman D (2011) The effects of air pollution and irritants on the upper airways. Proc Am Thorac Soc 8: 101-105.

102. Rex MAE (1970) A review of the structural and functional basis of laryngospasm and a discussion of the nerve pathways involved in the reflex and its clinical significance in man and animals. Br J Anaesth 42: 891-899.

103. Kobal G, Hummel T (1998) Olfactory and intranasal trigeminal eventrelated potentials in anosmic patients. Laryngoscope 108: 1033-1035.

104. Homma I, Masaoka Y (2010) Respiratory response toward olfactory stimuli might be an index for odor-induced emotion and recognition. New Frontiers in Respiratory Control Advances in Experimental Medicine and Biology. Springer pp: 347-352.

105. Haines J, Esposito K, Lillie S, McNamee C, Pargeter N, et al. (2015) Position paper. Speech and language therapy in adult respiratory care. London.

106. Deckert J, Deckert L (2010) Vocal cord dysfunction. Am Fam Physician 81: 156-159.

107. Patel RR, Venediktov R, Schooling T, Wang B (2015) Evidence-based systematic review: Effects of speech-language pathology treatment for individuals with paradocical vocal fold motion. Am J Speech Language Pathology 24: 566-584.

108. Yumoto E (2004) Aerodynamics, voice quality, and laryngeal image analysis of normal and pathologic voices. Curr Opin Otolaryngol Head Neck Surg 12: 166-173.

109. Hertegård S (2005) What have we learned about laryngeal physiology from high-speed digital videoendoscopy?. Curr Opin Otolaryngol Head Neck Surg 13: 152-156.

110. Newman KB, Mason UG 3rd, Schmaling KB (1995) Clinical features of vocal cord dysfunction. Am J Respir Crit Care Med 152: 1382-1386.

111. Doshi DR, Weinberger MM (2006) Long-term outcome of vocal cord dysfunction. Ann Allergy Asthma Immunol 96: 794-799. 